\title{
ENTRE PROTECTORES Y OPOSITORES: LABOR POLÍTICA FRENTE AL CASO HONECKER
}

Between Protectors and Opponents: The Politics of Honecker's Case

\section{CRISTIÁN E. MEDINA VALVERDE}

Universidad San Sebastián (Chile)

\section{GUSTAVO GAJARDO PAVEZ}

Universidad San Sebastián (Chile)

\section{RESUMEN}

El artículo aborda el problema internacional que generó la entrada de Erich Honecker a la embajada chilena en Moscú en 1991. Este proceso se transformó en uno de los episodios más confusos de la historia de las Relaciones Internacionales contemporáneas de nuestro país. Analizamos los efectos políticos internos que tuvo el Caso Honecker centrándonos en dos grandes perspectivas: por un lado, el conflicto generado entre el Ejecutivo y el Legislativo en torno a la búsqueda de soluciones y, por otro, la posición de los partidos políticos frente a los hechos. La investigación se basa en una exhaustiva revisión de fuentes primarias oficiales obtenidas tanto del Archivo Histórico del Ministerio de Relaciones Exteriores de Chile (MINREL) como de las sesiones de la Cámara de Diputados, se incluye además la prensa del período.

Palabras clave: Chile, relaciones internacionales, Caso Honecker, Ministerio de Relaciones Exteriores, Cámara de Diputados, partidos políticos

\begin{abstract}
This article deals with the international fallout from Erich Honecker's entrance into the Chilean embassy in Moscow in 1991. This process became one of the most confusing episodes in the recent history of Chilean foreign affairs. The study analyzes the internal political effects of Honecker's case, focusing on two significant points of view: first, the conflict between the executive and legislative branches of government; and second, the positions adopted by political parties in response to the situation. The research is based on an exhaustive analysis of diplomatic primary sources, records from the Chamber of Deputies, and media archives.
\end{abstract}

Key words: Chile, foreign affairs, Honecker's case, Ministry of Foreign Affairs of Chile, Chamber of Deputies, political parties 


\section{INTRODUCCIÓN}

El desarrollo de las relaciones internacionales de un Estado no puede comprenderse a cabalidad sin estudiar cuál es el panorama interno del país en el momento de llevar a cabo cualquier estrategia hacia el exterior; este lazo es innegable. Por lo mismo este artículo se ha fijado la tarea de exponer y desarrollar las razones políticas e ideológicas que resultaron determinantes al tomar la decisión de recibir a Erich Honecker como huésped de la embajada chilena en Moscú en 1991. Analizamos también las consecuencias que esto tuvo en los actores políticos internos del período y que fueron relevantes a la hora de buscar una solución a un complejo episodio que colocó al gobierno de Patricio Aylwin en una situación incómoda e inesperada justo cuando despuntaba el retorno a la democracia en Chile.

La investigación se vertebra a partir de la información oficial recogida de las legaciones de Chile tanto en Bonn como en Moscú. Este último lugar fue donde se refugiaron Honecker y su mujer Margot por largos 231 días. Esta vertiente documental primaria se complementa con las diversas teorías del estudio de las Relaciones Internacionales y de la Ciencia Política.

Nos proponemos, más que hacer un simple relato histórico que describa cronológicamente los hechos ocurridos, ir más allá realizando un análisis detallado de las relaciones bilaterales entre Alemania, la Federación Rusa y Chile, entre los años 1991 y 1992, apuntando siempre esclarecer cuál fue la labor política nacional en torno de la relación del custodio del Muro de Berlín y nuestro país.

De este modo entregamos los lineamientos básicos que permiten comprender el desarrollo histórico del Caso Honecker, es decir, las razones que el exjerarca tuvo al huir de Alemania para intentar al menos asilarse en suelo ruso, situación que llevó finalmente a que terminara golpeando la puerta de la embajada chilena en Moscú. Los hechos acaecidos terminaron por desviar la mirada internacional hacia Chile, país que recibió a un acusado por crímenes contra los Derechos Humanos. Posteriormente profundizamos en el papel desempeñado por el Poder Ejecutivo, específicamente por el Ministerio de Relaciones Exteriores y sus legaciones, haciendo hincapié en la importancia de los personajes que manejaron desde el principio este problema. Por último, analizamos las críticas que desde la Cámara de Diputados se realizaron en contra del accionar de la Cancillería frente al problema planteado, destacando las diferentes posiciones que los partidos políticos chilenos tomaron frente al Caso Honecker.

\section{CONSIDERACIONES PREVIAS}

Erich Honecker fue uno de los personajes importantes para comprender el desarrollo del conflicto ideológico, político, económico y militar entre el bloque occidental y el oriental durante los años de la Guerra Fría. Su presencia y 
relevancia como un nombre permanente a lo largo esos años se acrecentó de acuerdo con los cargos estatales que fue ocupando dentro del proyecto político que suscribió, la hoy extinta República Democrática Alemana (RDA).

Aun así, su incidencia, responsabilidades y protagonismo no solo se remiten a las décadas en que se prolongó el enfrentamiento ideológico entre las superpotencias; contrario a lo que pueda pensarse, luego del derrumbe del bloque soviético se comenzó a gestar un nuevo capítulo de las Relaciones Internacionales globales. En efecto, después de la unificación alemana el gobierno de Helmut Kohl buscó hacer justicia frente a los delitos cometidos en la RDA, y tuvo especial atención a las violaciones a los Derechos Humanos. En ese aspecto no debe extrañar que todas las miradas apuntaran al exjerarca socialista como el principal responsable.

Así, y en un período singularmente breve, Erich Honecker pasó de ser el Secretario General del Partido Socialista Unificado (Sozialistische Einheitspartei Deutschlands) y Presidente del Consejo de Estado de la RDA, a ser un ciudadano alemán perseguido por su responsabilidad como principal custodio del muro de Berlín. En solo semanas el proyecto marxista de Estado terminó por derrumbarse sobre sus pilares y la enfermedad que en un principio había sido excusa para que el partido lo destronara y luego expulsara a Honecker comenzó a mermar su calidad de vida (Diez y Martín de la Guardia 1998; Corvalán 2000).

El 10 de agosto de 1990 fue acusado formalmente por el tribunal de Berlín de homicidio y lesiones múltiples, por lo que se redactó una orden de detención en su contra. Es necesario mencionar que sus problemas con la ley en esta renovada Alemania en vías de reunificación ya habían comenzado unos meses antes, desde que a fines de 1989 se inició una causa en su contra por corrupción, alta traición y abuso de poder durante los dieciocho años que se mantuvo en la cúspide de la política de la RDA.

Inmerso en este escenario, Honecker y su esposa Margot viajaron a Moscú por razones de salud, pero también escapando de la justicia germana. Es en este punto donde el problema evoluciona de ser un tema judicial nacional a transformarse en un conflicto internacional entre Alemania y la entonces Unión Soviética (URSS). Esta última había gestionado raudamente el viaje del "camarada" bajo promesa de tratamiento médico y asilo diplomático, todo con tal de evadir su responsabilidad en el banquillo de los acusados (Corvalán 2000: 98). Aun en este punto, ninguna de las partes involucradas hasta ese momento tenía certeza de la veracidad de la enfermedad que aquejaba a Honecker, menos su naturaleza y seriedad. Quizás por ello las autoridades alemanas se apresuraron en solicitar su extradición inmediata.

Por su parte, la situación política interna de la URSS era poco alentadora; pasaba por convulsiones bastante complejas y se acercaba de modo inexorable el fin del dominio del Kremlin sobre una parte del mundo. Como es de suponer esto no favoreció para nada la situación de los Honecker, pensando que el destino 
del viaje había sido motivado por la cercanía ideológica con Moscú, que ahora tenía problemas internos más urgentes de los que ocuparse más que velar por la protección de un extranjero que había perdido la detentación del poder. En lo inmediato, la firma del asilo formal que buscó el exlíder alemán nunca se concretó, por lo que Honecker envió una carta a Mijaíl Gorbachov explicando su situación. En ella decía:

La RDA era un estado soberano, reconocido internacionalmente, incluso por la RFA. Sus fronteras eran las fronteras occidentales del tratado de Varsovia, el cual hasta su disolución constituía una comunidad reconocida según el derecho internacional y cuya existencia después de la fundación de la OTAN aseguró, en última instancia, la paz en Europa y en el mundo durante 45 años. (...) En cuanto a la cuestión de mi extradición, yo quisiera declarar que no volveré a Alemania hasta que sea levantada la orden de captura. (...) hoy quisiera solicitar a la dirección soviética, quiera apoyar con todos los recursos que se dispone, nuestro deseo de unión con nuestra familia en Chile (Corvalán 2000: 188).

Esta misiva no tuvo respuesta de parte del estado soviético por lo que al huésped germano se le acababan las opciones. Ante este adverso escenario y seguro Honecker de que no tenía un futuro prometedor en Moscú, solicitó autorización para salir desde la URSS hacia un tercer país, que era Chile. Fue su primera opción en tanto su hija Sonja y su nieto residían en Santiago, pero su petición fue negada. Es evidente que Honecker respaldó sus decisiones apelando a su supuesto delicado estado de salud (Kramer 1995).

Finalmente, al ser notificado de su expulsión definitiva de territorio soviético, Honecker acudió a las dependencias de la embajada chilena en Moscú para manifestar su situación a las entidades correspondientes, solicitando auxilio y protección. El gobierno chileno tomó la determinación de escucharlo y el 11 de diciembre de 1991 el matrimonio hacía ingreso a la legación en calidad de "huéspedes de residencia" (MINREL 1991, N 560) la situación obligó a Honecker a realizar una declaración oficial explicando su situación:

He tomado conocimiento a través de los medios de comunicación de una declaración del gobierno de Chile según la cual no se me brindaría asilo político. Al respecto deseo aclarar que hasta la fecha nunca he solicitado asilo político a Chile, sino que he pedido únicamente que se me permita ingresar a ese país para permanecer con mi familia (MINREL 1991, N 564).

Ahora bien, la entrada de Chile al conflicto posibilita realizar un análisis temprano, de acuerdo con las diferentes visiones teóricas de las Relaciones Internacionales, sin olvidar lo multidisciplinario de su estudio. A pesar de esta heterogeneidad de variables, consideramos necesario investigar el proceso político que produjo el Caso Honecker para Chile teniendo presente un único edificio teórico (Fermandois 2014). 
Por lo tanto, el realismo proporciona la libertad y rigor necesarios para comprender un proceso tan complejo para las relaciones entre Estados. Esta visión aleja idealismos innecesarios en el momento de realizar el análisis y además es más cercana a la relación con la historia, con la que se logra una complementación. Todo ello proporciona claridad en las conclusiones a las que se pueda llegar (Palomares 1994: 81-86; Barbé 1995; Ortiz 2000; Pereira 2008).

\section{LA TENSIÓN DIPLOMÁTICA}

El gobierno de Patricio Aylwin asumió como uno de sus objetivos principales volver a posicionar a Chile dentro de un escenario internacional pues, como ha sido expuesto, se encontraba sometido durante ese período a profundos cambios políticos globales. En los dos primeros años de gobierno este postulado se cumplió progresivamente: nuestro país mantenía buenas relaciones bilaterales con naciones cuyos vínculos se encontraban rotos y también se estaban construyendo excelentes relaciones multilaterales, al participar activamente en convenciones y grupos internacionales. En 1991 se comenzó a hablar de una política exterior cumplida en su primera etapa, en tanto se había logrado eficientemente volver a reinsertar a Chile en el escenario político internacional, por lo que los esfuerzos de la Cancillería giraron levemente a una inserción de tipo comercial, fomentando y planificando asociaciones internacionales (Milet 2012: 317).

(...) Tenemos la convicción de que estamos avanzando por la buena senda, sin que nos inspiren afanes protagónicos, sino tan solo el anhelo de participar constructivamente en la comunidad internacional, inspirados en el deseo de cooperar en pro del mejor entendimiento entre todas las naciones. Reitero, nuevamente, que en este ámbito, más que en ningún otro, el gobierno aspira y hace todo lo necesario para que nuestra política exterior constituya una política de estado, fruto de un gran consenso nacional, por encima de las diferencias partidistas. Creemos, de este modo, servir con la mayor lealtad y eficacia, los superiores intereses de Chile (Mensaje Presidencial 1991: 15).

El primer gobierno de la Concertación, además, debió hacer frente a las repercusiones jurídicas y políticas del régimen militar y buscó la forma de avanzar hacia la justicia y la reconciliación por las numerosas violaciones a los derechos humanos. Esto influyó también en el desarrollo de las relaciones internacionales de la época. Siendo estrictos, no es posible comprender el desarrollo de una política exterior en contrariedad y divergencia con el devenir del acontecer interno del país. Esta realidad terminó con la impugnación provocada por el gobierno anterior y mejoró notablemente la imagen de Chile (Durán y Wilhelmy 2003: 280). Tomando en consideración las aspiraciones internacionales del gobierno chileno, el Caso Honecker no solo dificultó la labor del Ministerio de Relaciones Exteriores (MINREL), sino que además complicó 
los planes de reposicionar a Chile como un Estado democrático responsable y justo frente al concierto internacional.

El MINREL es el núcleo principal de la organización y aplicación de la política exterior. En él se administran los lineamientos como un reflejo de los ideales del Estado y por ende del gobierno. Se formulan estrategias y se ejecutan de acuerdo con lo planificado. Cumple las funciones de centralizar los intereses del Estado y de la sociedad total en el plano internacional, recopila y evalúa la información, la generación de opciones para su posterior elección por el Gobierno, la comunicación constante con otras entidades de similar labor y la explicación de las decisiones políticas a otros países del mundo (Pereira 2008: 608).

El encargado de la cancillería durante el gobierno de Aylwin fue el político radical y abogado Enrique Silva Cimma, mientras que el democratacristiano Edmundo Vargas Carreño fue designado como Subsecretario de Relaciones Exteriores. Se trataba de un experimentado diplomático que fue además director de la Academia Diplomática de Chile. Por su parte, el embajador chileno en Bonn, durante el desarrollo de la situación Honecker, fue Carlos Huneeus, quien tuvo que sobrellevar y transmitir las constantes presiones del gobierno federal de Kohl a Santiago (MINREL 1992, Nº02). Por último y más relevante aun, los diplomáticos designados en Moscú y que tuvieron que ver en forma directa con la entrada del ex mandatario alemán hasta su salida en 1992 fueron el embajador Clodomiro Almeyda Medina, político de larga carrera en el partido socialista (Almeyda 1987) y José Miguel Cruz, que era el encargado de negocios y consejero de la legación chilena en suelo moscovita y responsable de abrir las puertas al matrimonio Honecker (MINREL 1991, N 560).

La posición oficial del gobierno respecto de la situación de Honecker como huésped del Estado chileno, formada de acuerdo con los informes de los funcionarios en la misión diplomática en Moscú, fue comunicada a la opinión pública por el Canciller subrogante Edmundo Vargas:

El 11 de diciembre se presentó en la residencia de Chile en la URSS Erick Honecker (...) Por encontrarse en Chile el embajador Clodomiro Almeyda, el señor Honecker informó al encargado de negocios del país que debía abandonar el territorio ruso a más tardar el día 13 del presente mes, de lo contrario sería expulsado por la fuerza a la RFA (...) en vista de la situación descrita por el sr. Honecker fue recibido en calidad de huésped en nuestra embajada (El Mercurio 1991: A20).

Haciendo especial referencia a los objetivos y labores del MINREL antes mencionados, consideramos que la comunicación e interconexión con el exterior, es decir con las misiones diplomáticas en Bonn y Moscú, fue absolutamente vital para un proceso político tan complicado como el que desató el acoger a un perseguido por crímenes y violaciones contra los Derechos Humanos. A la vez, la estrecha relación entre las embajadas de Chile en la Federación Rusa y 
en Alemania con las respectivas Cancillerías de tales Estados fue crucial para el devenir y pronta solución de este problema diplomático.

La información transmitida entre las entidades chilenas en el exterior y el MINREL fue muy expedita, a juzgar por los numerosos télex, oficios, instrucciones oficiales, cartas directas y la prensa, enviadas hacia y desde Chile. Estos documentos contenían todos los detalles posibles de los hechos ocurridos durante la estadía del matrimonio Honecker en la legación chilena, además de las opiniones y declaraciones de los Estados involucrados. Esta fluidez en la comunicación generó una red enlazada en pos de lograr una solución que perjudicara lo menos posible a nuestro país.

El número de documentos oficiales en torno a la relación entre Honecker y Chile es muy amplio, pero aquí son interesantes los más relevantes para este caso. La reacción de la opinión pública y social moscovita fue todo un aspecto dentro de las negociaciones entre Bonn y Santiago, e incluso se materializó en movilizaciones y manifestaciones populares en las cercanías de la embajada chilena, lo que obviamente dificultó la estadía del matrimonio alemán.

Infous para esta noche se ha anunciado manifestaciones frente nuestra embajada de grupos que pedirían se entregue al Sr. Honecker a autoridades de Federación Rusa. Asimismo habría concentración de partidarios que solidarizan con el Sr. Honecker y que desean impedir su salida de nuestra embajada (MINREL 1991, Nº 573).

Para disminuir la gravedad del problema la Cancillería chilena tomó la tajante determinación de prohibir a los Honecker las declaraciones de todo tipo a los medios de prensa que se apostaban cerca de la misión, a excepción de cuando fuera un comunicado oficial de la embajada. Por lo tanto, el propio Honecker realizó un breve análisis y balance de su situación en torno a los requerimientos e insistencias de la justicia alemana que solicitaba vivamente a Chile que, a través de las autoridades rusas, lo entregara para su juicio.

Entre la Unión Soviética y la RFA no existe un convenio de extradición, como tampoco entre Rusia y la RFA, por dicha razón, este gobierno no tiene motivo para considerar tal exigencia, ni menos aún para satisfacerla, ya que según el derecho internacional, las personas perseguidas por razones políticas no deben ser entregadas (MINREL 1991, N 565).

Como se mencionó en el apartado anterior, la URSS atravesaba serias convulsiones políticas, que la llevaron finalmente al derrumbe, transformándose en una renovada Federación Rusa y, por lo tanto, Honecker era un verdadero dolor de cabeza para su política. Que nuestro país fuera responsable por su futuro fue un alivio para los rusos, que se desligaron casi por completo del caso, según lo comunicó la embajada chilena: 
El gobierno de Alemania debe entrar en contacto con la embajada de Chile en Moscú para encontrar una salida a la situación que se ha formado en torno a Erich Honecker que se encuentra allí (...) Los chilenos no van a echar a Honecker fuera de la embajada. Si así es, La Federación Rusa no tiene nada que ver aquí, entonces esto es ya caso de Chile y Alemania (MINREL 1991, N 580).

A cientos de kilómetros de Moscú, la embajada chilena en Bonn también era blanco directo de las presiones alemanas, lo que llevó a Huneeus a mantener un contacto continuo con las autoridades locales, e incluso se reunió con el mismo Presidente alemán Richard Von Weizsäcker, con el Subsecretario de Asuntos Políticos del Ministerio de RR.EE., Dieter Kastrup y con el Encargado de Relaciones con América Latina, Gerhard Henze, para discutir sobre el futuro de este problema.

(...) Sobre particular me preguntó qué haríamos para solucionar este caso y también sobre razones que hacen del tema Honecker un aspecto sensible en la política interna chilena. En este sentido dio a entender claramente que ahora le corresponde a Chile tomar la iniciativa para dar movimiento a este asunto (MINREL 1992, $\mathrm{N}^{\circ}$ 008).

El estado de salud real de Honecker fue sin dudas el punto álgido de todo este proceso, ya que durante muchos meses no se tuvo certeza absoluta del padecimiento que lo aquejaba. Este fue uno de los motivos para que surgiera en Chile una patriada de defensores de Honecker, que presionaban para que se le otorgara el asilo diplomático formal y para que viajara a Chile a tratarse, bajo "motivos humanitarios", es decir, ir en su ayuda porque estaba gravemente enfermo.

La embajada chilena siempre veló por mantener al huésped en las mejores condiciones, incluso fue trasladado a una clínica para ser examinado y tratado adecuadamente. Todos los gastos médicos del señor Honecker fueron considerados como egresos del presupuesto de la Embajada, o sea fueron pagados por Chile. Estas expensas ascendieron a la suma total de US\$ 4.369, según lo especificó Almeyda al MINREL. Si consideramos el valor del dólar en 1992, la factura le costó a nuestro país 1.584 .112 pesos (MINREL 1992, Nº 004).

Toda la correspondencia expuesta anteriormente es el fiel reflejo de la labor constante delMINRELfrentea este caso, y revela cómolas legaciones diplomáticas correspondientes se encargaron de formar una ágil red de información con la misión de solucionar prontamente el Caso Honecker, evitando así perjudicar directamente el devenir de la política exterior del gobierno chileno en plena apertura hacia el mundo. 


\section{LABOR LEGISLATIVA VERSUS LABOR EJECUTIVA}

La profundidad y complejidad de este problema traspasó raudamente las fronteras para impactar en la política interna de nuestro país. Gradualmente se ha ido estructurando y analizando cada arista de este conflicto. Pero ¿qué sucede cuando el Legislativo critica abiertamente la mala gestión de la Cancillería, e incluso del propio Aylwin? ¿O cuando las versiones de la entidad responsable de Honecker como huésped de Chile no coinciden?

Como era de esperar, la estadía del matrimonio alemán en la embajada no fue permanente y terminó abandonando las dependencias chilenas para ser entregado a las autoridades rusas. Erich Honecker viajó a Berlín para sentarse definitivamente en el estrado, mientras Margot llegó a Santiago y se instaló junto a su hija Sonja. Las declaraciones oficiales del gobierno chileno respecto de este acontecimiento fueron unas de las más relevantes y sujetas a debates, como bien lo retrató la revista Qué Pasa (1992):

Quiero agregar que el señor Honecker se retiró en forma absolutamente voluntaria de la embajada (Enrique Silva Cimma).

No cabe duda que se le quitó la calidad de huésped a Honecker. Chile le declaró que la calidad de huésped era temporal (Patricio Aylwin).

Esta nota de prensa expone la contradicción que existía dentro del mismo gobierno tras el término de un capítulo del caso Honecker, mientras Silva Cimma, ministro de Relaciones Exteriores, hablaba de abandono voluntario, el entonces Presidente Aylwin, ocho días después, aducía que había sido el gobierno el que decidió poner fin a la tan prolongada hospitalidad. Las declaraciones de dos de los máximos responsables del caso son contrarias solo con días de diferencia, lo que revela al menos una falta de coordinación del aparato político estatal chileno al momento de planificar una salida al tema y la existencia de diferentes intereses políticos.

Además estas líneas vislumbran otro factor refutado posteriormente por la Cámara de Diputados. Nos referimos a la evidente incapacidad y desconexión de Silva Cimma como canciller. La salida de Honecker de la legación solo sirvió como ebullición de ideales políticos contrarios, que llevaron a fragmentar peligrosamente la estabilidad de la Concertación en torno a las disímiles opiniones sobre el juicio de Honecker y a la posibilidad de un viaje a Chile, lo que nuevamente se postergó por su ida a Alemania (Análisis 1992, marzo: 22-23).

La procedencia y formación de los diplomáticos chilenos se ha ido conformando como un tema bastante recurrente en el momento de analizar las relaciones internacionales de los últimos 24 años. Clodomiro Almeyda se desempeñó como embajador dado que su partido formaba parte de la coalición gobernante, la Concertación de Partidos por la Democracia; pero también a que poseía cierta experiencia diplomática. 
Almeyda no fue el encargado de solucionar este caso, a pesar de lo vigente de su cargo. Aylwin designó solo cuatro días después de la entrada de los huéspedes a la legación a James Holger Blair como embajador especial, quien fue clave en el curso que el asunto tomó en los siguientes meses al asumir la responsabilidad de solucionar de la mejor forma posible esta crisis. Holger era abogado, cientista político y doctor en Historia, además de funcionario diplomático desde 1949. Por lo tanto, era un agente diplomático profesional sin filiación política pero con una vasta experiencia para llevar a buen puerto los intereses de Chile. Como bien lo determinó Aylwin: “(...) Es un profesional capacitado para resolver el Caso Honecker" (Qué Pasa 1992, junio: 15).

De esta forma, el presidente apostó por un funcionario más capacitado, con trayectoria y que finalmente se ubicara por encima del embajador oficial Almeyda. Más aún, el político socialista viajó a Santiago por petición personal de Aylwin para hacer uso de sus vacaciones. Esta fue una estrategia del Ejecutivo para no enemistarse con el Partido Socialista, que representaba una sensibilidad relevante dentro de la Concertación. Era claro que una eventual destitución de Almeyda podía amenazar las relaciones en el interior de la alianza gobernante. Como se ve, el caso Honecker fue mucho más que el de solo un huésped inusual pernoctando dentro de las puertas de una embajada a miles de kilómetros de Santiago.

En nuestro país, uno de los principales responsables de las gestiones del caso Honecker no fue, como podría pensarse, Silva Cimma, a pesar de ser la cabeza visible de la Cancillería. El entonces secretario General de Gobierno Enrique Correa tomó cierto control en cuanto a la relación de Honecker y Chile.

La visión de Correa sobre las gestiones internacionales dependía de alcanzar la estabilidad. En sus propias palabras: "Queremos volver a ser un país normal y respetado en la comunidad internacional; que seamos invitados por presidentes del todo el mundo, y que el nuestro sea bienvenido donde quiera que vaya (Heine 1991: 3).

El episodio ocurrido en la Embajada de Chile en Moscú supuso también un enfrentamiento al interior de Chile entre el Poder Legislativo y Ejecutivo, este quedó registrado en las sesiones de la Cámara de Diputados espacio donde se analizaron los acontecimientos considerando las consecuencias que ello traería para el país.

El 5 de agosto de 1992 se trató exclusivamente al caso Honecker. A tal reunión asistió el ministro Silva Cimma para exponer prolongadamente cada detalle de la gestión que la Cancillería llevó durante los meses de refugio del exjerarca alemán. Solo al abrir la sesión los parlamentarios se enfrascaron en una acalorada discusión, ya que acompañando al ministro de Relaciones Exteriores asistió su subsecretario, Edmundo Vargas, al que no se le permitió entrar a la sala aún después de varias votaciones a mano alzada. 
En tal ocasión, la discusión se inició por discrepancias en torno a la presencia de los ministros de Estado; el entonces presidente de la Cámara, José Antonio Viera-Gallo aclaró de inmediato que solo se había invitado al canciller y que no era una citación. Por lo mismo, el diputado democratacristiano Sergio Elgueta declaró: "El señor ministro, como su señoría bien ha dicho, es un invitado que no es acusado ni es testigo que pueda ser interrogado por los señores fiscales que se pretenden erigir en esta sesión" (Cámara de Diputados 1992, Sesión $25^{\mathrm{a}}$ : 2.032). Incluso llegó a hablarse de un cuestionario de doce preguntas que algunos parlamentarios tenían preparado para que Silva Cimma respondiera con el fin de que asumiera toda la responsabilidad.

Las críticas hacia la Cancillería fueron bastante duras. Se calificó el episodio Honecker como una de las etapas más penosas y vergonzosas de la historia de la buena diplomacia nacional, en donde la imagen de Chile había resultado seriamente perjudicada. Además, se consideró que el gobierno pudo y debió evitar socorrer al político alemán ya que, finalmente, luego de que los siete meses de refugio fueran inútiles, el longevo invitado igual terminó compareciendo ante la justicia federal.

Parte del Legislativo pedía insistentemente que se dieran a conocer todos los detalles de este "absurdo caso". En palabras del diputado de Renovación Nacional (RN), Jorge Morales Adriasola:

El manejo dado por la cancillería y, en general por el gobierno chileno, plagado de contradicciones, llevan a pensar que primaron los intereses políticos internos por sobre la política exterior chilena. (...) La cancillería nos demostró, además desde un comienzo, su incapacidad para evaluar la gravedad y urgencia del caso y su falta de claridad respecto de los principios jurídicos que debían conducir su acción (Cámara de Diputados 1992, Sesión 25a: 2.033).

Otroaspecto sujetoa los ataques dealgunos parlamentarios fueel correspondiente a la misión de Chile en el plano internacional. Como ya hemos mencionado, por entonces se estructuraba una política exterior de apertura, responsabilidad que caía sobre los hombros del Ejecutivo y, por ende, de la Cancillería, precisamente los organismos sujetos a cuestionamientos. Así lo había asegurado el Presidente Aylwin en su momento, al decir que:

(...) Dentro de este marco, la política internacional de Chile, que mi gobierno concibe como política de Estado -inspirada en criterios nacionales, por encima de tendencias partidistas- persigue como objetivos fundamentales colaborar a la causa de la paz en el mundo sobre la base de los principios del Derecho Internacional, y fortalecer la amistad y cooperación entre las naciones (Mensaje Presidencial 1992: 16).

La política exterior de un Estado debe centrarse bajo un ideal de fuerza mayor, que a su vez debe estar determinado por un bien común o, mejor llamado, "interés nacional". Considerando la posición internacional prometedora de Chile hacia 
1991, no convenía por ninguna circunstancia generar un problema adicional (¿artificial?) con Alemania por el futuro del exlíder de la RDA (Fermandois 1991; Rojas 1997; Durán y Wilhelmy 2003; Fermandois 2006; Artaza y Ross 2012; Van Klaveren 2011).

Lo cuestionable es precisamente eso: al recibir a Honecker en la legación, no se pensó ni por un minuto en el bien del país, se actuó por la cercanía ideológica entre Irma de Almeyda y José Miguel Cruz, por el lado chileno, y el matrimonio alemán. Pero también se hizo dado que fue la Alemania de Honecker la que brindó refugio y hospitalidad a muchos exiliados chilenos.

Esto inmediatamente perjudicó la imagen de la Cancillería chilena y a la vez del país ante el escenario mundial.

\section{PARTIDOS POLÍTICOS FRENTE AL CASO}

La relación entre Honecker y nuestro país no solo tuvo sus efectos en la política exterior de Chile, sino también en el balance y buen funcionamiento de la maquinaria política interna. Los enfrentamientos, opiniones y declaraciones de los diversos partidos políticos chilenos fueron impulsados por las diferentes posiciones ante el futuro de este conflicto internacional. Luego de la salida del matrimonio alemán de la embajada, esta situación estalló y centró al Ejecutivo como blanco de las críticas de todos los sectores.

La derecha presentó inmediatamente su escrutinio sobre las consecuencias del caso para el país. Se consideró el episodio Honecker como nocivo para el desarrollo de buenas y prósperas relaciones internacionales. Por lo tanto, RN calificó a la cancillería de incapaz e inútil frente a este proceso de "hospedaje" que terminó generando varios perjuicios.

Las críticas del gremialismo no se hicieron esperar; los diputados de la Unión Demócrata Independiente (UDI) destacaron con mayor ahínco el pésimo manejo del caso Honecker y presionaron para que Silva Cimma aclarara todas las dudas de un capítulo que, según consideraban, dañaba a la patria. Así lo expresó Juan Antonio Coloma:

Nos parecen desde ya inaceptables para la esencia de lo que constituye nuestra soberanía las informaciones que aseguran que el señor Honecker fue acogido inicialmente bajo nuestra bandera por la sola decisión de quienes dependían del Embajador señor Almeyda, sin consulta previa a la Cancillería chilena (Cámara de Diputados 1992, Sesión 25ª: 2.035).

La derecha respaldó la concepción de que la política exterior debe responder a un interés general del país, situación que no se vio en el momento en que Almeyda o, mejor dicho, su mujer Irma y su círculo asesor más cercano en la legación, decidieran actuar sin consultar previamente al MINREL, órgano que debería haber decidido cómo proseguir. Este aspecto fue -en su interpretación- 
una grave muestra de personalismo. Además se consideró inaceptable que luego de tal error, Almeyda mantuviera su condición de embajador por varios meses.

El juicio gremialista fue un tanto apresurado, ya que posteriormente y ante la inminente llegada de un Honecker enfermo a Chile, su apreciación cambió de manera radical. La UDI terminó aprobando las decisiones del gobierno, ya que las consideraron un acto humanitario frente a un anciano verdaderamente enfermo. Julio Dittborn, en ese momento presidente del Comité Ejecutivo del partido, ratificó que no podía negársele la ayuda a alguien necesitado, pero que se mantenía la crítica al Poder Ejecutivo por sus gestiones (La Nación 1993). Claramente fueron los conglomerados de la oposición los más críticos de la actuación del gobierno.

Por su parte, el Partido por la Democracia (PPD), que era parte del gobierno, en voz del diputado Felipe Valenzuela apeló a que nuestro país poseía una tradición "asiladora". Un año antes ya habían declarado su apoyo total para que Honecker fuera asilado oficialmente por Chile. En tal ocasión se refirieron a que el país históricamente se había inclinado a proteger a quienes lo necesitaran, por medio del asilo diplomático, como sucedió con los exiliados españoles de la Guerra Civil (Cámara de Diputados 1991, Sesión 34ª 3.236-3.237).

La expulsión de Honecker de la Federación Rusa, como fue calificada por el PPD, constituyó realmente una extradición, lo que contradijo la versión oficial del MINREL. Su fundamento se basó en la presencia de funcionarios de seguridad rusos dentro de la embajada chilena, que supuestamente presionaron a la pareja de ancianos para que salieran. En suma, la visión de este partido hacia el proceso afirmaba que se debió brindar el asilo político en el mismo instante en el que Honecker ingresó a la legación chilena (Cámara de Diputados 1992, Sesión 25ª).

Las profundas divisiones en las colectividades políticas nacionales se evidenciaron, a modo de ejemplo, en la situación interna del PPD. Su presidente, Jorge Schaulsohn, representó la posición oficial del partido, que era visiblemente disímil de la planteada anteriormente por el diputado Valenzuela, que dijo:

El derecho de asilo no puede ser invocado por actos opuestos a los propósitos y principios de Naciones Unidas. La violación a los derechos humanos son opuestos a los propósitos y principios de las Naciones Unidas, de modo que el asilo político no correspondía ni corresponde en el caso del señor Honecker, quien está donde debe estar, ante un tribunal independiente de un estado democrático para responder por las atrocidades cometidas durante su dictadura (...) (Cámara de Diputados 1992, Sesión 25a: 2.044).

A pesar de las evidentes discrepancias internas, el PPD terminó otorgando abiertamente todo el apoyo a las gestiones del gobierno de Aylwin, incluido el MINREL y a Silva Cimma, lo que diferenció su opinión de la derecha. Bajo esta perspectiva, la determinación de dar "hospedaje" a Honecker fue la mejor 
opción, ya que era necesario que en algún momento el exlíder de la RDA se responsabilizara por los cargos imputados.

La posición del Partido Socialista (PS) es particularmente compleja, ya sea por la cercanía ideológica que profesaban con Honecker, porque era la tienda política del exembajador Almeyda, o bien porque muchos de sus militantes habían vivido su exilio en la RDA. Luego de la entrada de Honecker a la embajada, el socialismo chileno presionó al gobierno para que hiciera asilar al invitado, de un modo formal, permitiéndole viajar a Chile con privilegios diplomáticos y de lo contrario amenazaron con retirarse de la Concertación. Esto habría sido un duro golpe para la estabilidad de la coalición que gobernaba, ya que en esa época el PS era uno de los pilares de esta alianza. Una vez más se evidencian las constantes presiones de las que era víctima el gobierno de Aylwin: internacionalmente desde Alemania y la opinión pública mundial e internamente por los partidos políticos tanto de la oposición como de la Concertación.

La opinión pública criticó el accionar de Almeyda, lo que puso un manto de duda sobre sus capacidades como político. Ante la idea del Ejecutivo de que removerlo de su cargo como representante ante la Federación Rusa seguro provocaría la ira del socialismo chileno, se envió al mencionado James Holger como funcionario especial y no como remplazo definitivo de Almeyda. De haberlo sido, Aylwin hubiese tenido que enfrentar un declarado frente interno. En suma, el caso Honecker provocó la primera tensión interna de la Concertación desde su llegada al poder (Hoy 1992).

Finalmente, el diputado Camilo Escalona expresó una perspectiva más fiel a los ideales de la desaparecida RDA, si consideramos que fue uno más de los exiliados tras el muro de Berlín. Interpelando la postura adoptada por la oposición y presentando su discrepancia con la salida de Honecker de la embajada, dijo:

En el fondo hemos quedado prisioneros de una comedia de equivocaciones. La de la derecha, al vestirse hoy con un ropaje democrático, que no tiene; de una parte de ella al hacer escarnio de la política internacional del Gobierno de la Concertación, la misma que no pudo ser desarrollada por la dictadura, un régimen opresivo que indujo el más profundo aislamiento de Chile en el concierto internacional como nunca antes en su historia (Cámara de Diputados 1992, Sesión 25a: 2.060).

Semanas antes, en pleno apogeo del conflicto por el asilo o la expulsión del exjerarca, una delegación parlamentaria alemana visitó nuestro país dentro de un marco de integración política, lo cual generó instancias directas de discusión con los connacionales de Honecker y sirvió para conocer su postura en torno al caso. El tema salió a la palestra en el primer encuentro entre diputados, que fueron recibidos por el parlamentario DC Juan Carlos Latorre, pues el caso Honecker representaba, al igual que para los chilenos, una preocupación de Estado para los germanos. En la ocasión, el presidente del Senado, Gabriel Valdés, planteó su análisis de la crisis internacional. 
(...) Se refirió en términos muy francos al caso Honecker, repitiendo su posición personal contenida en su declaración del mes de diciembre de 1991, insistiendo que el problema debía encontrar pronta solución. A su juicio, esta situación coyuntural no debía perturbar las sólidas y tradicionales buenas relaciones bilaterales (MINREL 1992, $\mathrm{N}^{\circ} 24$ ).

Como queda demostrado, el escenario político interno fue duramente golpeado por los efectos colaterales del caso Honecker. Bajo esta premisa, el ministro Silva Cimma se encargó de defender la gestión del gobierno y cumplir las órdenes según lo requerido por Aylwin respecto de Honecker, lo que nuevamente demostró esa cierta incapacidad del presidente para delegar responsabilidad en su gabinete y asesores, asumiendo él todo el peso de una crisis tan importante. El canciller hizo presente al Legislativo que el gobierno jamás planteó el asilo y, según la versión del gobierno, solo fue huésped de la misión diplomática, en calidad de temporal.

La estabilidad del sistema político nacional se balanceaba debido a las incontables desavenencias partidistas que el caso Honecker provocó, situación que se gestó ad portas de procesos democráticos tan relevantes como la elección municipal del 28 de junio de 1992 y las determinaciones por saber quién representaría a la Concertación en las próximas elecciones presidenciales de 1993 (Análisis 1992: 8-9).

\section{CONSIDERACIONES FINALES}

El caso Honecker puede analizarse desde diversas perspectivas. Entre ellas, la jurisprudencia aclarará las complejidades de este proceso para el derecho internacional; por otro lado, la historia entregará todas las herramientas necesarias para investigar los documentos oficiales, reconstruir el problema con sus detalles y ofrecer una interpretación plausible. Con todo, es la política la protagonista absoluta de todo lo que se relacionó con la situación del exlíder alemán y Chile. Este problema político tensionó de modo innecesario las relaciones internacionales en el retorno a la democracia de Chile, justo en la etapa en que la imagen del país en el exterior ascendía paulatinamente.

El caso Honecker presenta, además, algunas peculiaridades. En lo jurídico, Alemania construyó un caso en el que se le acusaba de crímenes y violaciones contra los derechos humanos ocurridas bajo su mandato, solo por su responsabilidad como líder en esa época. Estas nefastas agresiones ocurridas contra sus ciudadanos al momento de tratar de huir hacia Occidente se habían llevado a cabo en territorio de la RDA, un Estado que había dejado de existir desde 1989. Por lo tanto, el caso que la justicia federal había articulado carecía de jurisdicción, además de ser esta una de las razones por las cuales Honecker se negaba a enfrentarse a los jueces. Si a este factor, no menor, se le agrega que finalmente era cierto que el exjerarca socialista se encontraba desahuciado, se comienza a hablar inmediatamente de que, en su calidad de enfermo grave y por su avanzada edad, Honecker no podía pagar con presidio, respaldándose 
en razones humanitarias. Precisamente esto fue lo que ocurrió cuando la justicia alemana cerró el caso en 1993.

Si nos remitimos a la labor del gobierno chileno frente al caso Honecker, es claro que en las primeras horas en que Chile fue protagonista no se actuó correctamente y se hizo de manera inconsulta. Se obvió el aviso y permiso del MINREL antes de tomar alguna decisión y solo se actuó recibiendo al matrimonio que requería asistencia, para luego avisar a nuestra Cancillería en una clara política de hechos consumados. El episodio denota una muestra de personalismo de Almeyda, su esposa y el asesor Cruz. La cercanía ideológica o la necesidad de retribuir la ayuda que brindó la RDA a los exiliados chilenos primó por sobre el interés del país en los asuntos internacionales.

La profundidad de este problema trajo consigo fuertes repercusiones para la política interna, entre ellas divisiones entre los partidos políticos que se apresuraron a defender o atacar la labor del gobierno en torno a las gestiones de este caso. Los más repudiados por esto fueron evidentemente Enrique Silva Cimma, como responsable de la falta de cohesión y homogeneidad en las decisiones de la Cancillería, y el mismo presidente Aylwin, por su incapacidad de controlar y designar responsabilidad en sus subalternos.

Los vaivenes políticos incluso se evidenciaron en el interior de la Concertación, coalición que vivió la primera crisis desde su formación. Las amenazas y presiones del PS también hicieron evidente la preeminencia de lo ideológico en el momento de tratar un tema internacional tan controvertido, bajo la premisa de ayuda humanitaria cuando aún no se tenía certeza absoluta de ella. En suma, el caso Honecker marcó deliberadamente la labor política en todos los frentes, tanto en el desempeño del aparato ministerial, que terminó con Silva Cimma como el ministro peor evaluado del período, como de la Cámara de Diputados en tanto mantuvo una postura crítica frente al desempeño del gobierno y de los partidos políticos, que se enfrentaban entre sí por Honecker, entre otros.

Por último, la labor parlamentaria en torno a las relaciones internacionales es muy importante y es fundamental la coordinación y diálogo entre los poderes del Estado, sobre todo cuando se está frente a una crisis de la envergadura que tuvo el caso Honecker. Esta situación permite realizar un análisis más profundo y acabado de los temas discutidos, tal como sucedió en 1992 a raíz de la salida de Honecker de la embajada: era necesario realizar un balance del episodio, aclarar responsabilidad y planificar el devenir de las perjudicadas relaciones exteriores de Chile. Esta clase de debate, dentro de un marco de respeto y en un contexto histórico adecuado, se constituye como uno de los principales aspectos de la democracia. 


\section{REFERENCIAS}

\section{Fuentes oficiales}

\section{Ministerio de Relaciones Exteriores de Chile (MINREL):}

MINREL. 1991, 11 de diciembre. Télex Secreto Urgente N 560, Gobierno de Chile, Embajada en Federación Rusa, Moscú.

MINREL. 1991, 12 de diciembre. Télex Ordinario Urgente Nº 564, Gobierno de Chile, Embajada en Federación Rusa, Moscú.

MINREL. 1992, 8 de enero. Télex Reservado Rutina No 002, "Extradición de Honecker", Gobierno de Chile, Embajada en Alemania, Bonn.

MINREL. 1991, 16 de diciembre. Télex Ordinario Rutina Nº 573, Gobierno de Chile, Embajada en Federación Rusa, Moscú.

MINREL. 1991, 12 de diciembre. Télex Ordinario Urgente No 565, “Declaración Sr. Erich Honecker", Gobierno de Chile, Embajada en Federación Rusa, Moscú.

MINREL. 1991, 17 de diciembre. Télex Ordinario Urgente N 580, Declaraciones Canciller de Rusia sobre Caso Honecker, Gobierno de Chile, Embajada en Federación Rusa, Moscú. MINREL. 1992, 10 de enero. Télex Secreto Urgente Nº 008, Honecker, Gobierno de Chile, Embajada en Alemania, Bonn.

MINREL. 1992, 29 de abril. Oficio Reservado Nº 004, Comprobante de Contabilidad N ${ }^{o}$ 229, Gobierno de Chile, Embajada en Federación Rusa, Moscú.

MINREL. 1992, 2 de junio. Oficio Reservado N²4, "Relaciones diplomáticas Alemania". Gobierno de Chile, Embajada en Alemania, Bonn.

\section{Sesiones Parlamentarias}

Cámara de Diputados. 1991, 17 de diciembre. Sesión 34ª . Procedencia de Calidad de Huésped otorgada a Erich Honecker, Valparaíso.

Cámara de Diputados. 1992, 5 de agosto. Sesión 25a . Situación planteada por la permanencia del señor Erich Honecker en la embajada chilena en Moscú, Valparaíso.

\section{Mensajes Presidenciales}

Mensaje Presidencial. 1991, 21 de mayo. La reinserción internacional de Chile. Santiago.

Mensaje Presidencial. 1992, 21 de mayo. Chile en el mundo: Nuestra política internacional. Santiago.

\section{Prensa}

Análisis. 1992, 16 de marzo. Los traspiés de la cancillería. Santiago.

Análisis. 1992, 6 de julio. El drama se fue de vacaciones. Santiago.

El Mercurio. 1991, 13 de diciembre. Chile mantendrá como huésped a Erick Honecker. Santiago.

Hoy. 1992, 16 de marzo. El Motín socialista. Santiago.

La Nación. 1992, 30 de julio. Santiago.

La Nación. 1993, 14 de enero. Honecker llega hoy. Santiago.

Qué Pasa. 1992, 15 de junio. La hora del profesional. Santiago

Qué Pasa. 1992, 10 de agosto. 


\section{Referencias bibliográficas}

Almeyda, Clodomiro. 1987. Reencuentro con mi vida. Santiago: Ornitorrinco.

Barbé, Ester. 1995. Relaciones Internacionales. Madrid: Tecnos.

Corvalán, Luis. 2000. La otra Alemania, RDA: Conversaciones con Margot Honecker. Santiago: Ical.

Diez, José Ramón y Ricardo Guardia. 1998. Historia contemporánea de Alemania 1945-1995. Madrid: Síntesis.

Durán, Roberto y Manfred Wilhelmy. 2003. “Los principales rasgos de la política exterior chilena entre 1973 y el 2000". Revista de Ciencia Política XXIII(2): 273-286.

Fermandois, Joaquín. 1991. "De una inserción a otra: política exterior de Chile, 1966-1991". Estudios Internacionales 96: 433 - 455.

Fermandois, Joaquín. 2006. "Inserción Global y Malestar regional: la política exterior chilena en el ciclo democrático, 1990-2006". Estudios Internacionales 154: 91-99.

Fermandois, Joaquín. 2014. "Realidad latinoamericana y ser latinoamericano en las relaciones intrarregionales". Ponencia presentada en Seminario América Latina, Entre el desequilibrio y el orden. Universidad Católica de la Santísima Concepción. 7 de mayo.

Heine, Jorge. 1991. ¿Timidez o pragmatismo? La politica exterior de Chile en 1990. Santiago: PROSPEL.

Irigoin, Jeannette. 2012. "Política exterior y derecho internacional”. En M. Artaza y C. Ross (eds.). La política exterior de Chile 1990 - 2009. Del aislamiento a la integración global. Santiago: RIL editores, 187-207.

Kramer, Raimund. 1995. “De una diplomacia desaparecida: La política exterior de la República Democrática Alemana y sus relaciones con América Latina". Estudios Internacionales 110: 174-197.

Milet, Paz. 2012. "La política exterior de Chile: Enfoque histórico 1990 - 2010”. En M. Artaza y C. Ross (eds.). La política exterior de Chile 1990 - 2009. Del aislamiento a la integración global. Santiago: RIL editores, 317-336.

Ministerio de Relaciones Exteriores. 1992. La política exterior de Chile, 1990 - 1992. Santiago: Ministerio de Relaciones Exteriores.

Ortiz, Eduardo. 2002. El estudio de las relaciones internacionales. Santiago: Fondo de Cultura Económica.

Palomares, Gustavo. 1994. Teoría y concepto de las relaciones internacionales. Madrid: Universidad Nacional de Educación a Distancia.

Pereira, Juan Carlos. 2008. Diccionario de Relaciones Internacionales y Política Exterior. Barcelona: Ariel.

Rojas, Francisco. 1997. "Chile: Cambio político e inserción internacional 1964 - 1997". Estudios Internacionales 119-120: 376-406.

Serra, Andrés. 1998. Diccionario de Ciencia Política. México: Fondo de Cultura Económica.

Van Klaveren, Alberto. 2011. "La política exterior de Chile durante los gobiernos de la Concertación (1990-2010)". Estudios Internacionales 169: 155-172.

Cristián Medina Valverde: Doctor en Historia, Universidad Complutense de Madrid, Licenciado en Historia, Pontificia Universidad Católica de Chile. Profesor Investigador, Instituto de Historia, Facultad de Ciencias Sociales y Humanidades, Universidad San Sebastián (Chile). Correo electrónico: cristian.medina@uss.cl

Gustavo Gajardo Pavez: Licenciado en Historia, Licenciado en Educación, Profesor de Historia, Geografía y Ciencias Sociales, Diplomado en Filosofía Política. Correo electrónico: g.gajarpavez@ gmail.com 